\title{
Images from the Haematologica Atlas of Hematologic Cytology: bone marrow metastases from malignant melanoma
}

\section{Rosangela Invernizzi}

University of Pavia, Pavia, Italy

E-mail: ROSANGELA INVERNIZZI - rosangela.invernizzi@unipv.it

doi:10.3324/haematol.2021.280521

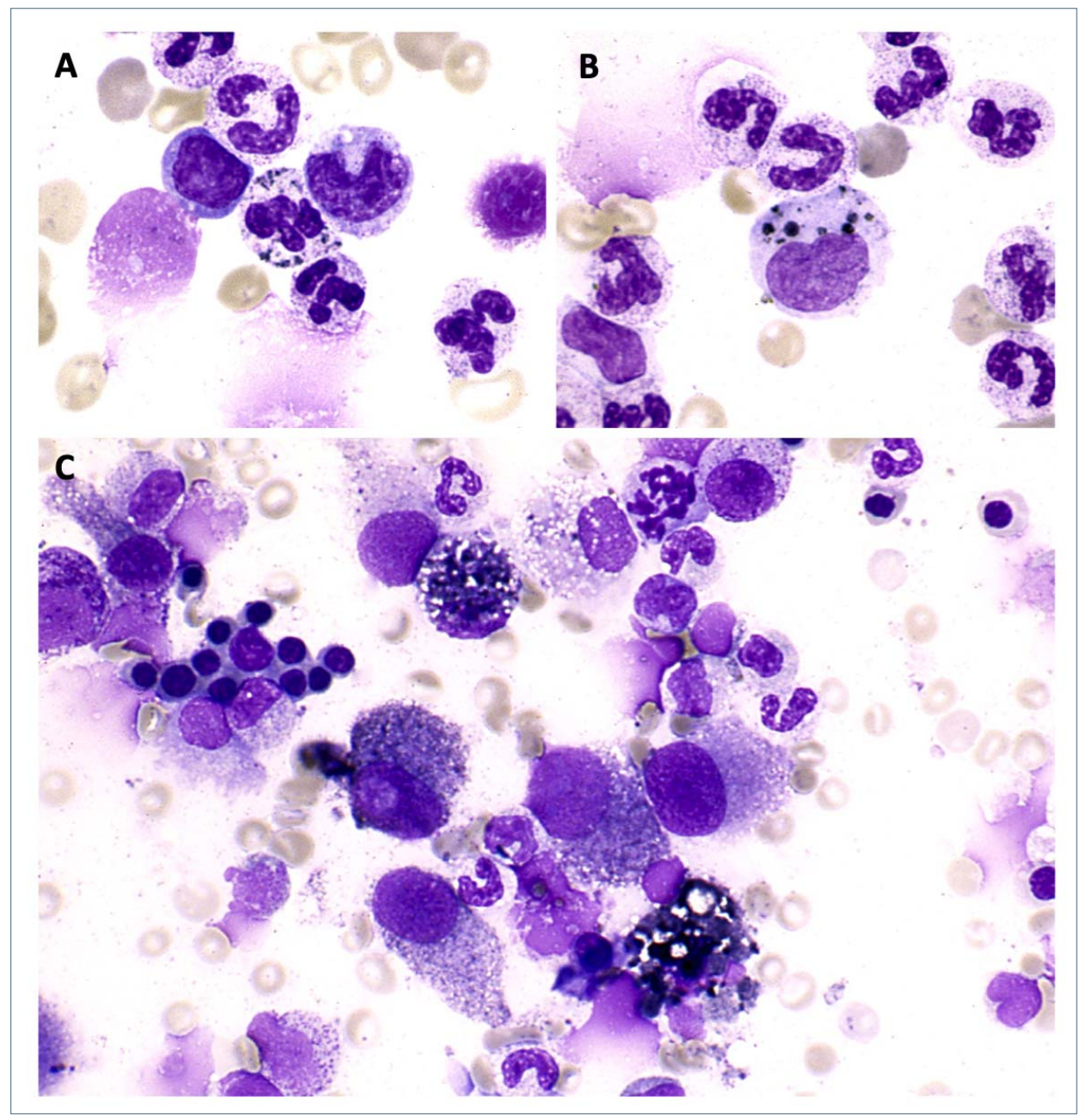

Tn some patients with malignant melanoma, neutrophils and monocytes can phagocytize the melanin deposits released by melanoma cells infiltrating the bone marrow and carry them into circulation, thus suggesting that the bone marrow is affected. In this patient with severe pancytopenia, who, 10 years before, had undergone surgery for cutaneous melanoma, a buffy coat smear shows granules of melanic pigment in the cytoplasm of a neutrophil (Figure A) and a monocyte (Figure B). The bone marrow smear demonstrates the presence of some large cells with round nuclei, prominent nucleoli, and abundant cytoplasm containing many very fine black granules. Melanin is also present in macrophages (Figure C). These findings confirm the diagnosis of a bone marrow relapse. It should be noted, however, that, not infrequently, metastatic malignant melanoma is amelanotic with cells that cannot be distinguished morphologically from other neoplastic cells. ${ }^{1}$

\section{Disclosures \\ No conflicts of interest to disclose}

\section{Reference}

1. Invernizzi R. Metastases of solid tumors. Haematologica. 2020;105(Suppl 1):261-269. 